\title{
Universal Use of Face Masks and Related Challenges During COVID-19 in Developing Countries
}

This article was published in the following Dove Press journal: Risk Management and Healthcare Policy

\author{
Gudina Terefe Tucho (D) \\ Diribe Makonene Kumsa ${ }^{2}$ \\ 'Department of Environmental Health \\ Sciences and Technology, Jimma \\ University, Jimma, Ethiopia; ${ }^{2}$ Department \\ of Sociology, Jimma University, Jimma, \\ Ethiopia
}

Background: Governments have imposed physical and social distancing measures together with hand hygiene to contain COVID-19. However, maintaining the recommended social distancing less likely applicable in developing countries where the majority of the people depend on daily income. Countries like Ethiopia imposed universal use of face masks as an additional measure.

Aim: This study aims to review and present the advantage and challenges of imposing universal use of face masks in the community and to forward possible recommendations.

Methods: The study was synthesized using a narrative literature review approach involving COVID-19 databases, published literature on COVID-19, and relevant news.

Results: The first confirmed case of COVID-19 in Ethiopia was reported on March 13, 2020. Consequently, the government has taken swift actions including social distancing and strict hygienic measures to contain its transmission. However, new cases have started to increase with local transmission. Hence, the country imposed additional measures including universal use of face masks at public places. The universal use of masks requires a sufficient supply of masks with affordable costs. Moreover, awareness of the proper use of face masks and its disposal is another challenge affecting its effectiveness against corona virus infection. Conclusion: Universal use of face masks can contribute to the containment of the virus in the community if adequately available and properly used and managed after use. Encouraging local production with clear guidance, demonstration, and awareness creation helps to improve the accessibility and effectiveness of face masks particularly among the vulnerable population.

Keywords: universal use, face mask, COVID-19, challenges, Ethiopia

\section{Introduction}

On March 11, 2020, the World Health Organization (WHO) has declared the novel corona virus (COVID-19) outbreak a global pandemic at a news briefing held at its headquarter. ${ }^{1}$ COVID-19 is a new public health crisis that originated in bats and transmitted to humans through unknown intermediary animals in Wuhan, China in December $2019 .^{2}$ The disease has spread over several countries of the world with millions of confirmed cases and hundreds of thousands of deaths. ${ }^{3}$

The world is not new for pandemic diseases, several pandemics have occurred in the past far and near times. ${ }^{4}$ All of these pandemics had left unforgettable memories in the world. COVID-19 is a global pandemic with a complicated viral character to contain. It kills healthy adults in addition to people with existing health
Correspondence: Gudina Terefe Tucho Department of Environmental Health Sciences and Technology, Jimma

University, Jimma, Ethiopia

Tel +25I9II703978

Email guditerefe@gmail.com
Risk Management and Healthcare Policy 202I:14 5II-517

submit your manuscript

DovePress f in 口 
problems and its transmission is quite efficient with an exponential rate of increase. ${ }^{5,6}$ Moreover, the human corona viruses can persist on inanimate surfaces like metal, glass, and plastic for up to 9 days. ${ }^{7,8}$ The study also shows the stability of the corona virus in water and wastewater. ${ }^{9}$ The corona virus is stable in a $\mathrm{pH}$ range of 3-10 and on plastic surfaces up to 72 hours. ${ }^{8,10}$ However, inactivation of the virus is possible with surface disinfection procedures involving $71 \%$ ethanol, $0.5 \%$ hydrogen peroxide or $0.1 \%$ sodium hypochlorite in 1 minute, and at a higher temperature. ${ }^{7,8}$

COVID-19 indiscriminately attacks people of all ages and all nations and transmitted by inhalation and contact with infected droplets. The incubation period of the disease varies from 2 to 14 days. Symptomatic patients and asymptomatic people can transmit the corona virus through droplets during coughing and sneezing. ${ }^{6,11}$ Many people infected by the COVID-19 virus might not develop symptoms of illness. Those developed the symptom of the disease usually experience high-grade fever, cough, sore throat, breathlessness, fatigue, and malaise. The disease is severe among chronic disease patients and old age people due to their decreasing immune system. Most of these patients often die of their original comorbidities. ${ }^{1,2}$ The disease could pose severe consequences in developing countries, where healthcare facilities and services are poor.

Most countries of the world have applied case detection, quarantine, and social distancing measures to reduce the transmission of the virus. These measures were effective to contain the virus and reduce new infections in many developed countries. ${ }^{12}$ Countries that applied strict social distancing have reduced new cases by more than $90 \%$ in a short time. ${ }^{12,13}$ However, the infectivity of the virus during the incubation period and its transmission from asymptomatic people ${ }^{2}$ enforce many countries to declare a complete lockdown. Countries in the developing world also considered social distancing measures to contain the virus. ${ }^{14}$ However, in countries like Ethiopia where over $20 \%$ of the population rely on less than $\$ 1.90$ a day and the majority of the urban rely on a daily income ${ }^{15}$ imposing lockdown cannot be a possible solution. Hence, additional measures are needed to reach out to vulnerable groups in the population. Ethiopia has imposed universal use of face masks in public areas in addition to considering strict hand hygiene and social distancing measures. The universal use of face masks by the general population could help to prevent the transmission of the virus from pre-asymptomatic and asymptomatic individuals. ${ }^{16,17}$
Studies show that use of face masks by healthcare workers and by the general population can reduce the risk of respiratory virus infection by $80 \%$ although its protective effectiveness varies between different areas. ${ }^{18}$ Another literature review study involving a total of 23,892 participants across 15 studies from 11 countries shows varying effectiveness surgical masks against acute respiratory infection but larger reduction was observed among consistent users. ${ }^{19}$ The effectiveness of face masks against COVID-19 was proven without significant protective effect of N95 respirator and surgical masks. ${ }^{20,21}$ Use of face masks is highly recommended at a community setting to prevent corona virus and other respiratory infections. ${ }^{22}$ However, the universal use of face masks is a new culture for the country to implement at the community level. Enforcing the universal use of face masks may also involve several challenges attributed to the socioeconomic and cultural conditions of the country. The purpose of this study is to evaluate conditions enforcing universal use of face masks and associated challenges in the effort of preventing corona virus infection and to forward possible remedies. The analysis is helpful to create an insight into the effectiveness of universal use of face masks and related challenges jeopardizing the COVID-19 prevention efforts.

The study was synthesized using a narrative literature review approach involving COVID-19 databases, published literature, and relevant news. Most countries in the world have taken COVID-19 control measures immediately following new case confirmation. Accordingly, the second section of the paper shows the steps the Ethiopian government has taken and current trends of new COVID-19 cases. The third section describes conditions enforcing universal use of face masks as additional measures in the country, and the fourth section discusses the challenges associated with the universal use of face masks in the community. The last section will provide concluding remarks with recommendations.

\section{Trends of COVID-19 New Cases in Ethiopia and Measures Taken Up to the Present}

The Federal Ministry of Health of Ethiopia has confirmed a case of corona virus disease (COVID-19) in Addis Ababa and announced on the 13th of March 2020. ${ }^{23}$ It is the first case to be reported in Ethiopia since the beginning of the outbreak in China in December 2019. Upon first case detection, the country immediately established the COVID-19 Emergency Operations at Ethiopian Public Health Institute 


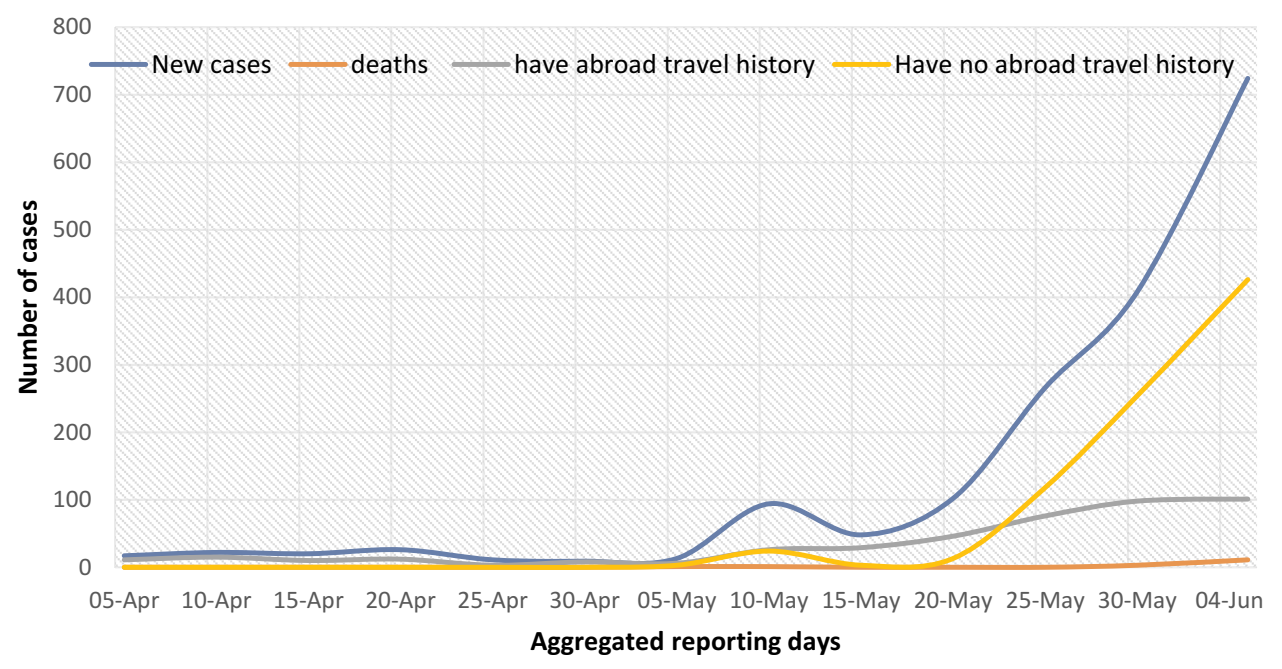

Figure I Trends of COVID-19 cases in Ethiopia at the beginning of the pandemic.

(EPHI) who is working closely with the Ministry of Health and the WHO. Following that, the country has adopted certain measures to control the transmission of the virus. The measures include thorough hand washing, use of alcohol-based hand sanitizer, physical distancing, and home-stay for individuals suspecting themselves. Closure of schools, universities, and shifting working hours was also considered to strengthen the social distancing measures. Establishments of COVID-19 rapid task forces at different levels of government institutions and regional offices were immediately implemented to act on local prevention. The taskforces were mandated to facilitate public awareness creation, case identification, and contact tracing, logistic mobilization and management, and COVID-19 test centers establishment. The taskforces at different levels were instructed to work closely with the local health offices and the ministry of health.

However, the country could not implement the social distancing measures as planned due to the following factors. First, the country could not provide sufficient urban transport to overwhelming vulnerable groups of the population striving for daily income. Second, the country could not control land transportation across borders although 14 days quarantine has been imposed on people coming to the country on airplanes. Thirdly, controlling market places and other public services was not possible. These factors were significant to affect the prevention efforts made at different levels. Until mid of May 2020, the progress of the disease was very slow and most of the cases were individuals with the history of abroad travel. However, after the mid of May 2020, the new cases have started to increase with cases having no history of abroad travel and contact with known cases.
Between the mid of May and the beginning of June 2020, the new cases have grown by 6-folds, where new cases with no history of abroad travel and known contacts have increased by 27 -folds (Figure 1). The increasing new cases with more local transmission and rapid dissemination of the disease mainly reported from the urban areas. ${ }^{24}$ This indicates the ineffectiveness of social distancing measures in urban areas due to the unwillingness of vulnerable people to stay at home. ${ }^{25}$ Moreover, enforcing poor people to stay at home leads to massive starvation, malnutrition, and deprivation of essential basic needs. Hence, the country sought additional harm-reduction options like the universal use of face masks as additional measures to reduce the spread of the virus.

Data source ${ }^{24}$

\section{Conditions Enforcing Universal Use of Face Masks in Developing Countries}

Physical distancing is recommended to be within about 2 meters distance between individuals at any public and job to prevent infection of the virus. However, social distancing may not be applicable and close contact is inevitable under some circumstances in developing countries. The majority of the poor in urban areas does not have permanent income and mostly rely on daily earning. These people mostly work in overcrowding conditions as daily laborers, in shantytowns, open-air markets, street vendors, and bars where recommended physical distancing cannot be maintained. The socioeconomic and political instability in the developing country put many people into refugee 
camps, prisons, and in street (homeless). Insufficient supply of public transportation services and unavailability of basic social services at near distances is another challenge making many people vulnerable to the disease. Lifestyle in developing countries mostly depends on the prevailing cultural and social structure where physical distancing is less likely possible. Segregation and isolation of individuals even at the presence of infection may lead to discrimination. Online learning and working from home are also not possible due to weak and unreliable internet connection; hence, physical communication is a must. When many people share a common living and working area, maintaining physical distancing could be less likely possible. Therefore, universal use of face masks needs to be applied as additional measures to contain the virus at source and reduce transmission of infections although a lot of challenges are involved.

\section{Challenges Related to the Universal Use of Face Masks in Developing Countries}

Upon recognizing the increasing trends of the diseases with new cases involving local transmission, Ethiopia considered additional measures by imposing a state of emergency lasting five-months. The additional measures include the universal use of face masks in public areas and during all activities. Accordingly, the Council of Ministers has approved a regulation that outlaw handshakes and obligates the universal use of face masks in public places. Non-compliance with the regulation could face a punishment of up to three years in jail or a fine of up to 200,000 birr. $^{26}$

Face masks are disposable personal protective equipment after one or two times use depending on the type of masks. ${ }^{27}$ In Ethiopia, about $20 \%$ of the population (about 23 million) lives in urban. These people are the most vulnerable individuals striving to satisfy their daily needs. Meeting their face masks demand requires the country to supply about 20-25 million pieces of face masks every 2-3 days. Hence, about 1.2 billion pieces of face masks are needed to meet the demand of the urban population during the emergency time (five months). Besides, the country disclosed the need for 131 million face masks to supply to healthcare facilities across the country during the emergency. ${ }^{26,28}$

Supplying face masks to all populations of the country (over 115 million) would be challenging in both supply and accessibility for the poor in a country. ${ }^{15}$ Moreover, the country mainly depends on aids to combat the spread of the disease and provide care to patients. For instance, the country has received 520,000 face mask donations from different Chinese business companies to supply to its health facilities. ${ }^{29}$ One of the important reasons for discouraging widespread and universal use of face masks by different countries was to preserve limited supplies of masks for professional use in health-care settings. ${ }^{17,30}$ Upon considering obligatory universal use of face masks, the country is required to have sufficient face masks and support the poor who are unable to afford in addition to the frontline health workers.

The shortage of disposable commercial face masks inevitably leads the country to shift to local production. Otherwise, washing and repeated use of the mask would likely increase the risk of getting the virus due to structural damage of the mask, contamination, and retention of the pathogens. ${ }^{27}$ It was argued that the universal use of face masks in the community provides less effective protection against corona virus infection due to improper use and not changing disposable masks. ${ }^{31}$ Poor people with subsistent income cannot afford frequent changing of their face masks. Poor people could be challenged to prioritize their basic needs for food and other life-supporting materials where COVID-19 prevention would be the second choice. To comply with law enforcement, people could be enforced to use sub-standardized face masks or repeated use of disposable masks. Such use of face masks gives false confidence and facilitates the transmission of the virus. Cloth masks made of appropriate cloths can be used and help to fight the virus when commercial disposable masks are scarce or unaffordable. ${ }^{27,32}$ However, there are a lot of concerns about the use of cloth masks' reusability and proper disinfection. The use of steam under pressure is the most practical approach to decontaminate cloth masks, ${ }^{33}$ but poor people do not have access to such disinfection facilities.

Moreover, used face masks are recognized as infectious healthcare wastes that should be discarded with special care. The Ethiopian government considered all wastes generated during care of COVID-19 cases as infectious waste and should be collected safely in designated containers, treated, and then safely disposed of..$^{34}$ Face masks are at high risk of capturing, retaining the virus, and becoming a source of infection during and after use. The universal use of face masks with repeated changes increases the volume of wasted face masks designated as infectious 
wastes. Moreover, appropriate waste management facilities are not available in developing countries to handle them. Managing these wastes according to its Standard Operating Procedures (SOP) would be very challenging at a community level. Hence, open field disposal together with other solid wastes likely increases the risk of acquiring the disease since the corona virus can stay in the open environment for several days. Further, waste pickers, scavengers, and children can easily get access to the face mask wastes probably containing the virus. The study indicated that discarded masks, gloves, and tissues are potential sources for the spread of corona virus resulting in indiscriminate infection. ${ }^{35}$

Nevertheless, the universal use of face masks remains a solution to poor people in developing countries to prevent them from the corona virus. When people wear face masks to protect themselves in close person-to-person contacts and unintentionally protecting each other through source control. An average person touches their face 23-26 times per hour spontaneously which use of the face mask can serve as a reminder to reduce hand-to-face contact. ${ }^{17}$ Any face masks made of cloth could be used when disposable commercial masks are not available, but clear guidance is needed on the selection of appropriate clothes for the masks. ${ }^{32,36}$ Viruses can survive on mask materials if contaminated during handling and may pose a risk of disease transmission. Hence, without proper management and guidance, the universal use of face masks by the community could jeopardize the prevention efforts of COVID-19. Means of overcoming the challenges associated with universal use of face mask is needed, which the following section focuses on.

\section{Means of Overcoming the Challenges}

Covid-19 is a new pandemic disease affecting all segments of the population. Many efforts are being made to contain the virus and save lives. All possible actions are contributing to the prevention efforts in progress. Nevertheless, the effectiveness of different measures varies based on the prevailing country's conditions. Effective measures in another country may not similarly work for others. Modification of the measures based on local conditions is needed to make it effective. The modification should focus on the vulnerable groups in the population who are striving for daily income. It has been tried that complete lockdown and homestay cannot work for the people striving for daily basic needs. Enforcing complete lockdown could shift the problem from dying of COVID-19 to dying of hunger and malnutrition. Hence, measures focusing on prevention at the source is the most appropriate and costeffective approach to prevent the transmission of the diseases. ${ }^{37}$ The universal use of masks integrated with strict hand hygiene and social distancing is appropriate to save lives while keeping vulnerable people at work. ${ }^{17,38}$ The universal use of face masks cannot substitute other measures but complement them by reducing infection at the source. However, the following actions are recommended to increase its effectiveness against corona virus infection prevention.

1. The capacity of local innovators and producers should be strengthened to produce standardized face masks from local materials to reduce supply gaps at an affordable price.

2. Continuous awareness creation and demonstration on how to use, when to use, how to disinfect, and dispose of used masks should be made at different community levels.

3. Used masks should be kept out of the reach of children and appropriately discarded after use.

4. Increasing the perception of the community that masks benefit only when social distancing and hand hygiene are properly practiced.

5. Encouraging and engaging private and government institutions to take care of their workers through the provision of face masks and cleaning materials.

\section{Conclusion}

COVID-19 indiscriminately attacks people of all ages and all nations. The disease is transmitted by inhalation or contact with infected droplets. The virus has a peculiar behavior, which makes its prevention very complex to manage with a simple preventive approach. Social and physical distancing measures together with hygiene practices are considered to contain the virus. Developing countries like Ethiopia also have taken similar measures, but could not continue to keep people at home and reduce the occurrence of new cases. The increasing new cases with local transmission enforced the country to declare a state of emergency involving universal use of face masks. The universal use of face masks can reduce the transmission of the virus at source and contribute to the containment of the disease. The effectiveness of universal use of face masks depends on a sufficient supply of face 
masks and its accessibility to the poor, proper use and handling after use. Continuous awareness creation and sensitization training on the proper use of face masks and its disposal should be made at all levels of the community. Familiarizing face masks with the community also helps future management of respiratory-related infectious diseases or similar future pandemics. Encouraging local production with clear guidance, demonstration, and awareness creation also needed to increase its accessibility and effectiveness against the virus.

\section{Author Contributions}

All authors contributed to data analysis, drafting or revising the article, have agreed on the journal to which the article will be submitted, gave final approval of the version to be published, and agree to be accountable for all aspects of the work.

\section{Disclosure}

The authors declare that they have no conflicts of interest.

\section{References}

1. Cucinotta D, Vanelli M. WHO declares COVID-19 a pandemic. Acta Biomed. 2020;91(1):157-160. doi:10.23750/abm.v91i1.9397

2. Singhal T. A review of coronavirus disease-2019 (COVID-19). Indian J Pediatr. 2020;87(4):281-286

3. WHO. World COVID-19 Update. 2020.

4. Hays JN. Epidemics and Pandemics: Their Impacts on Human History. Abc-clio; 2005.

5. Gates B. Responding to covid-19-a once-in-a-century pandemic? $N$ Engl $J \quad$ Med. 2020;382(18):1677-1679. doi:10.1056/ NEJMp2003762

6. Rothe C, Schunk M, Sothmann P, et al. Transmission of 2019-nCoV infection from an asymptomatic contact in Germany. $N$ Engl $J$ Med. 2020;382(10):970-971. doi:10.1056/NEJMc2001468

7. Kampf G, Todt D, Pfaender S, Steinmann E. Persistence of coronaviruses on inanimate surfaces and their inactivation with biocidal agents. J Hosp Infect. 2020;104(3):246-251. doi:10.1016/j. jhin.2020.01.022

8. Chin AWH, Chu JTS, Perera MRA, et al. Stability of SARS-CoV-2 in different environmental conditions. Lancet Microbe. 2020;1(1):e10. doi:10.1016/S2666-5247(20)30003-3

9. Gundy PM, Gerba CP, Pepper IL. Survival of coronaviruses in water and wastewater. Food Environ Virol. 2009;1(1):10. doi:10.1007/ s12560-008-9001-6

10. Van Doremalen N, Bushmaker T, Morris DH, et al. Aerosol and surface stability of SARS-CoV-2 as compared with SARS-CoV-1. $N \quad$ Engl $J$ Med. 2020;382(16):1564-1567. doi:10.1056/ NEJMc2004973

11. Zou L, Ruan F, Huang M, et al. SARS-CoV-2 viral load in upper respiratory specimens of infected patients. $N$ Engl J Med. 2020;382 (12):1177-1179. doi:10.1056/NEJMc2001737

12. Anderson RM, Heesterbeek H, Klinkenberg D, Hollingsworth TD. How will country-based mitigation measures influence the course of the COVID-19 epidemic? Lancet. 2020;395(10228):931-934. doi:10.1016/S0140-6736(20)30567-5
13. Remuzzi A, Remuzzi G. COVID-19 and Italy: what next? Lancet. 2020;395(10231):1225-1228. doi:10.1016/S0140-6736(20)30627-9

14. Organization WH. Coronavirus Disease 2019 (COVID-19): Situation Report. Vol. 72. 2020.

15. Commission EPaD. Poverty and Economic Growth in Ethiopia Between 1995-2016. Federal Democratic Republic of Ethiopia; 2018.

16. Bai Y, Yao L, Wei T, et al. Presumed asymptomatic carrier transmission of COVID-19. JAMA. 2020;323(14):1406-1407. doi:10.1001/ jama.2020.2565

17. Advani S, Smith B, Lewis S, Anderson DJ, Sexton DJ. Universal masking in hospitals in the COVID-19 era: is it time to consider shielding? Infect Control Hosp Epidemiol. 2020;41(9):1066-1067.

18. Liang M, Gao L, Cheng C, et al. Efficacy of face mask in preventing respiratory virus transmission: a systematic review and meta-analysis. Travel Med Infect Dis. 2020;36:101751. doi:10.1016/j. tmaid.2020.101751

19. Wang MX, Gwee SXW, Chua PEY, Pang J. Effectiveness of surgical face masks in reducing acute respiratory infections in non-healthcare settings: a systematic review and meta-analysis. Front Med. 2020;7:582. doi:10.3389/fmed.2020.564280

20. Howard J, Huang A, Li Z, et al. Face masks against COVID-19: an evidence review. 2020.

21. Chu DK, Akl EA, Duda S, et al. Physical distancing, face masks, and eye protection to prevent person-to-person transmission of SARS-CoV-2 and COVID-19: a systematic review and meta-analysis. Lancet. 2020;395(10242):1973-1987. doi:10.1016/ S0140-6736(20)31142-9

22. Gómez-Ochoa SA, Muka T. Meta-analysis on facemask use in community settings to prevent respiratory infection transmission shows no effect. Int $J$ Infect Dis. 2020;103:257-259. doi:10.1016/j. ijid.2020.11.139

23. WHO. First Case of COVID-19 Confirmed in Ethiopia. 2020.

24. EPHI. National Notification Nots on COVID-19 Situational Update. Ethiopian Public Health Institute; 2020.

25. Barnett-Howell Z, Mobarak AM. The benefits and costs of social distancing in rich and poor countries. arXiv Preprint arXiv. 2004;04867:2020.

26. Allafrica. Ethiopia Outlaws Handshakes, Obliges Masks in Public Places. 2020.

27. Li DTS, Samaranayake L, Leung YY, Neelakantan P. Facial protection in the era of COVID-19: a narrative review. Oral Dis. 2020. doi:10.1111/odi.13460

28. Africanews. Ethiopia Coronavirus: $131 \mathrm{~m}$ Masks Needed, Active Cases Pass 1000. 2020.

29. Xinhuanet. Ethiopia Receives Chinese Donation of 520,000 Masks, Medical Supplies. 2020.

30. Organization WH. Rational Use of Personal Protective Equipment for Coronavirus Disease ( COVID-19) and Considerations During Severe Shortages: Interim Guidance, 6 April 2020. World Health Organization; 2020.

31. Feng S, Shen C, Xia N, Song W, Fan M, Cowling BJ. Rational use of face masks in the COVID-19 pandemic. Lancet Respir Med. 2020;8 (5):434-436. doi:10.1016/S2213-2600(20)30134-X

32. Chughtai AA, Seale H, MacIntyre CR. Use of cloth masks in the practice of infection control-evidence and policy gaps. Int $J$ Infect Control. 2013;9(3). doi:10.3396/IJIC.v9i3.020.13

33. Ou Q, Pei C, Chan Kim S, Abell E, Pui DYH. Evaluation of decontamination methods for commercial and alternative respirator and mask materials - view from filtration aspect. J Aerosol Sci. 2020;150:105609. doi:10.1016/j.jaerosci.2020.105609

34. MoH. Health Care Waste Management SOP for COVID-19. 2020.

35. Adhikari SP, Meng S, Wu Y-J, et al. Epidemiology, causes, clinical manifestation and diagnosis, prevention and control of coronavirus disease (COVID-19) during the early outbreak period: a scoping review. Infect Dis Poverty. 2020;9(1):1-12. doi:10.1186/s40249020-00646-x 
36. Leung CC, Lam TH, Cheng KK. Mass masking in the COVID-19 epidemic: people need guidance. Lancet. 2020;395(10228):945. doi:10.1016/S0140-6736(20)30520-1

37. Kosior E, Crescenzi I. Chapter 16 - solutions to the plastic waste problem on land and in the oceans. In: Letcher TM, editor. Plastic Waste and Recycling. Academic Press; 2020:415-446.
38. Ramakrishnan D. COVID-19 and face masks - to use or not to use! Indian $J$ Community Health. 2020;32(2 (Supp)):240-243. doi:10.47203/IJCH.2020.v32i02SUPP.012

\section{Publish your work in this journal}

Risk Management and Healthcare Policy is an international, peerreviewed, open access journal focusing on all aspects of public health, policy, and preventative measures to promote good health and improve morbidity and mortality in the population. The journa welcomes submitted papers covering original research, basic science, clinical \& epidemiological studies, reviews and evaluations, guidelines, expert opinion and commentary, case reports and extended reports. The manuscript management system is completely online and includes a very quick and fair peer-review system, which is all easy to use. Visit http://www.dovepress.com/testimonials.php to read real quotes from published authors.

Submit your manuscript here: https://www.dovepress.com/risk-management-and-healthcare-policy-journal 